\title{
Chromosome 14 familial Alzheimer's disease: the clinical and neuropathological characteristics of a family with a leucine $\rightarrow$ serine (L250S) substitution at codon 250 of the presenilin 1 gene
}

\author{
Richard J Harvey, David Ellison, John Hardy, Mike Hutton, Penelope K Roques,
} John Collinge, Nick C Fox, Martin N Rossor

\begin{abstract}
Background-Seven affected members are described from a kindred with autosomal dominant familial Alzheimer's disease associated with a novel mutation in the presenilin 1 (PS1) gene on chromosome 14 that results in a leucine to serine substitution at codon 250 (L250S).

Method-Clinical information on the pedigree was collected directly from family members including affected members and their carers and also from hospital records.

Results-Detailed clinical information was available on five members. All had an early age at onset with a median age of 52 (95\% confidence interval (95\% CI) $49.4-$ 54.9). Age at onset varied between 49 and 56 years, with duration of illness varying between six years and 15 years. Myoclonus, depression, and psychosis were features of this pedigree; seizures were not reported.

Conclusions-PS1 L250S familial Alzheimer's disease is an early onset form of Alzheimer's disease with clinical features similar to other reported familial Alzheimer's disease pedigrees, except that seizures were absent.
\end{abstract}

(f Neurol Neurosurg Psychiatry 1998;64:44-49)

Keywords: presenilin 1; familial Alzheimer's disease; clinical features; chromosome 14

Alzheimer's disease is the most common dementia resulting in neuronal degeneration and the accumulation of amyloid plaques and neurofibrillary tangles in the cerebral and limbic cortices. Autosomal dominant familial Alzheimer's disease accounts for between 5\% and $15 \%$ of all cases of Alzheimer's disease. ${ }^{1}$ The first genetic locus to be identified in autosomal dominant familial Alzheimer's disease was on the amyloid precursor protein gene, ${ }^{2}$ although the locus was later shown to account for a minority of cases. The major group of families with early onset familial Alzheimer's disease was subsequently found to be linked to markers on chromosome $14 .^{3}{ }^{4}$ The responsible gene has recently been cloned and referred to as presenilin 1 (PS1); many pathogenic mutations cosegregating with familial Alzheimer's disease have now been identified..$^{5-13}$ After the discovery of the PS1 gene, a homologous gene was also identified on chromosome 1 (presenilin 2), mutations of which also result in autosomal dominant familial Alzheimer's disease. ${ }^{14-16}$

The recent advances in molecular genetics have established the considerable heterogeneity of familial Alzheimer's disease. This may be reflected in phenotypic heterogeneity with differences seen between the different major genetic loci $^{17}$ and also between allelic variants at specific loci. ${ }^{18} 19$ Such findings advance our understanding of brain-behaviour relations in Alzheimer's disease. In addition, however, it is important to determine to what extent information from individual familial Alzheimer's disease pedigrees with precise molecular pathology can be generalised to the commoner late onset sporadic cases.

Screening of the St Mary's and National Hospitals' collection of familial Alzheimer's disease pedigrees identified a family with a novel L250S mutation in the PS1 gene. ${ }^{13}$ We now report the clinical and neuropathological characteristics of this pedigree.

\section{Methods}

The Dementia Research Group at St Mary's Hospital Medical School and the National Hospital for Neurology and Neurosurgery has followed a programme of systematic identification, tracing, and extending of families with apparent autosomal dominant degenerative dementias. More than 250 families have been identified since 1986,150 of which are clinically familial Alzheimer's disease pedigrees. After the cloning of the PS1 gene, ${ }^{8}$ screening of our pedigrees with early onset familial Alzheimer's disease has identified mutations $^{5-13}$ which included a family (F184) with a novel mutation (L250S). Figure 1 shows the family tree. Clinical information was available for seven affected members, of which two were living and were assessed by the research team. Additional information was collected from hospital records and other family members. Histopathological confirmation of Alzheimer's disease was available in two affected members of the family.

Age at onset was defined as the age that a person first showed signs of memory loss or personality change and was estimated from the reports of family members and hospital records. The Medical Research Council guidelines for assessment of research patients with and in revised form

3 June 1997

Accepted 18 June 1997 


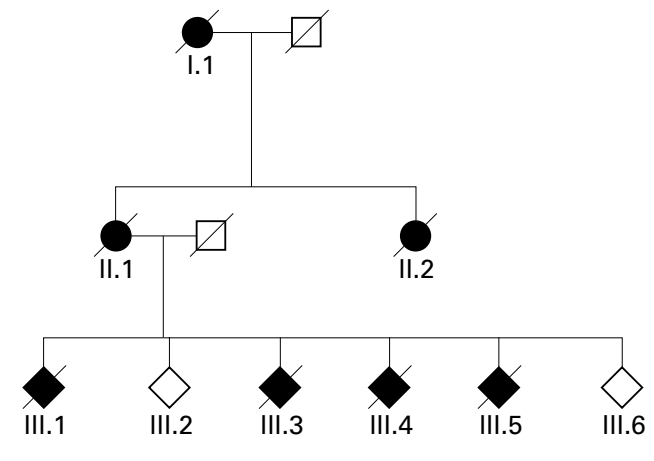

Figure 1 Family 184 pedigree.

Alzheimer's disease provided the basis for the clinical interview which also included the mini mental state examination (MMSE) and the clinical dementia rating (CDR). ${ }^{20-22}$ Whenever possible, the history was verified by an independent interview with the primary carer. Details of the onset, progression, and neurological and psychiatric symptoms were recorded. Case summaries were compiled from all available information. A blood sample from one affected member and one unaffected member from each pedigree was screened for PS1 mutations to confirm cosegregation of the mutation with the disease. The details of the genetic screening are described elsewhere. ${ }^{523}$ Neuropathological examination was carried out on two cases who came to postmortem examination.

\section{Results}

FAMILY OVERVIEW

As most of the affected members had died before the families volunteered for the research, clinical information was primarily obtained from hospital records and family members. One deceased affected member had undergone neuropathological examination and details of the histology were obtained. In addition, two affected members were assessed clinically, one of whom subsequently came to postmortem examination. The table gives data on age at onset and clinical features in the family. The Median age at onset was 52 (95\% confidence interval 49.4-54.9).
CASE REPORTS

Case 184.I.1 (female)

She died at the age of 58 having had a dementing illness.

Case 184.II.1 (female)

She had a 15 year illness associated with progressive memory and cognitive impairment. A diagnosis of presenile dementia was made and she died at the age of 66 in a psychiatric hospital.

Case 184.II.2 (female)

Very little information was available, but she was said by family members to be affected with a dementing illness and to have died in her early 60 s.

Case 184.III. 1

There was a 14 year history of dementia, with an onset at the age of 55, and death at the age of 69 .

\section{Case 184.III. 3}

The age at onset was 56 years and death occurred at the age of 63 years. The first symptom of the illness in this right handed retired factory worker was loss of confidence and an unwillingness to go out in public. Shortly after this, driving was given up because of worries about safety. Increasing forgetfulness prompted a medical opinion at the age of 58 . The patient was seen for the research study at the age of 60 . When assessed there was moderate dementia with poor memory, language impairment, and great difficulty recognising close members of the family. The subject would speak at great length, but made no sense. There was a history of visual hallucinations and symptoms of depression since the illness started, although no psychiatric treatment was given. The patient scored $0 / 30$ on the MMSE and was noted to have myoclonus. After death the brain was examined histologically and showed extensive senile plaque and neurofibrillary tangle formation confirming the NINCDS/ADRDA definite diagnosis of Alzheimer's disease.

Case 184.III. 4

The age at onset was 49 years, and age at death 55 years. This right handed care assistant first

Table 1 Age at onset and clinical features of family 184

\begin{tabular}{|c|c|c|c|c|c|c|c|c|c|c|}
\hline Subject & $\begin{array}{l}\text { Age }(y) \\
\text { at onset }\end{array}$ & $\begin{array}{l}\text { Age }(y) \\
\text { at death }\end{array}$ & $\begin{array}{l}\text { Age (y) } \\
\text { when } \\
\text { assessed }\end{array}$ & $\begin{array}{l}\text { Duration } \\
\text { of illness } \\
\text { (y) }\end{array}$ & $\begin{array}{l}\text { ApoE } \\
\text { genotype }\end{array}$ & $\begin{array}{l}\text { First } \\
\text { symptom }\end{array}$ & Other symptoms & Psychiatric features & Neurological features & Seizures \\
\hline 184.I.1 & - & 58 & - & - & - & & - & - & - & - \\
\hline 184.II.1 & 51 & 66 & - & 15 & - & & - & - & - & - \\
\hline 184.II.2 & - & $\begin{array}{l}\text { Early } \\
60 \mathrm{~s}\end{array}$ & - & & - & & - & - & - & - \\
\hline 184.III.1 & 55 & 69 & - & 14 & - & & - & - & - & - \\
\hline 184.III.3 & 56 & - & 60 & $>7$ & 3,4 & $\begin{array}{l}\text { Loss of } \\
\text { confidence }\end{array}$ & $\begin{array}{l}\text { Visual agnosia, language } \\
\text { impairment }\end{array}$ & $\begin{array}{l}\text { Visual } \\
\text { hallucinations, } \\
\text { depression }\end{array}$ & Myoclonus & 0 \\
\hline 184.III.4 & 49 & 55 & - & 6 & - & Memory & $\begin{array}{l}\text { Visual agnosia, language } \\
\text { impairment }\end{array}$ & 0 & $\begin{array}{l}\text { Myoclonus, } \\
\text { supranuclear } \\
\text { opthalmoplegia, } \\
\text { extrapyramidal signs }\end{array}$ & 0 \\
\hline 184.III.5 & 50 & - & 56 & $6+$ & - & Memory & Language impairment & $\begin{array}{l}\text { Visual } \\
\text { hallucinations, } \\
\text { depression }\end{array}$ & 0 & 0 \\
\hline
\end{tabular}

$+=$ Present $-=$ unknown; $0=$ absent. 


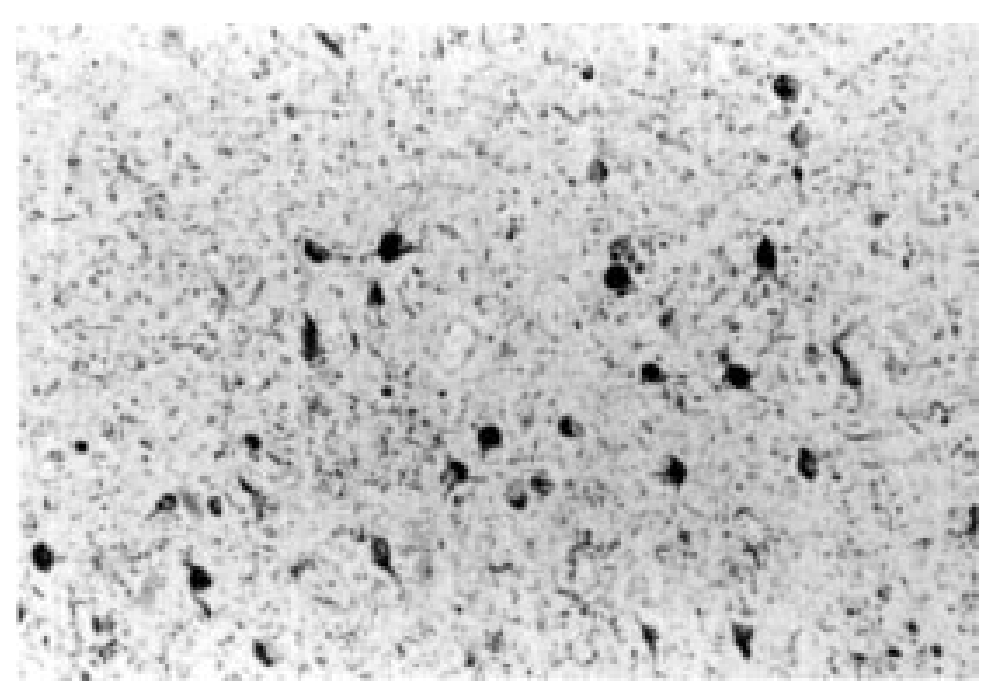

Figure 2 Patient III.4. neurofibrillary tangles were numerous in many cortical regions. This is the inferior temporal gyrus. (tau protein antibody).

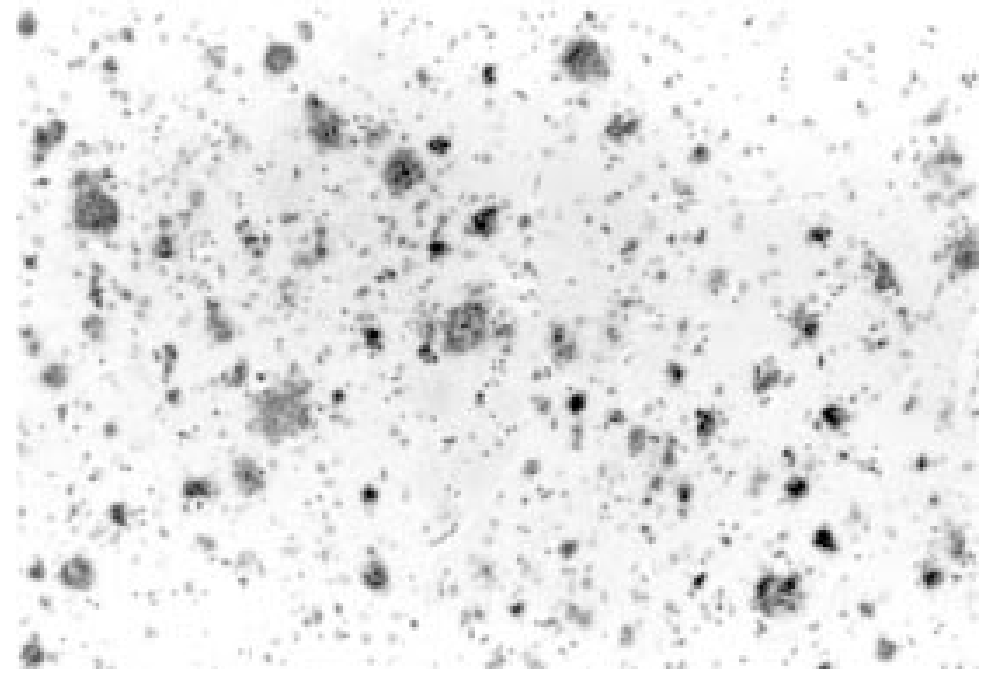

Figure 3 Patient III.3. Abundant senile plaques were present in the striatum ( $A \beta$ protein antibody). tangle formation in the frontal and temporal cortex, confirming the NINCDS/ADRDA definite diagnosis of Alzheimer's disease.

Case 184.III.5

The age at onset was 61 years with duration of illness 11 years. This right handed manual worker began to have problems with memory at the age of 50. Appointments would be forgotten and the patient was suspended from employment on two occasions because of dangerous behaviour. Assessment for the research was carried out at the the age of 53. At this time there was moderate dementia with an MMSE score of 15/30 and evidence of myoclonic jerks. Since the onset of the dementia there was reduced verbal output, memory impairment, and the development of a depressive illness requiring treatment with antidepressant medication. Visual hallucinations also developed, particularly the seeing of strangers in the room. Formal neuropsychological assessment showed a severe degree of intellectual deterioration with non-verbal skills affected to a greater extent. Memory function was extremely poor, together with dyscalculia, dysgraphia, apraxia, impaired visual perception, and poor performance on tests of frontal lobe function. By contrast language skills were relatively preserved. The patient died at the age of 61 and no postmortem was performed.

\section{COMPARATIVE HISTOPATHOLOGY}

Postmortem examination of the brains of patients III. 3 and III.4 both showed the typical features of Alzheimer's disease. However, unusually, macroscopically both brains showed symmetric cortical atrophy which was particularly severe in the frontal and temporal lobes; differing from the more usual pattern of temporoparietal atrophy.

The density of neurofibrillary tangles and senile plaques in the cerebral cortex of both patients was comparable. In the medial temporal lobes, immunohistochemistry with antibody to tau protien showed many neurofibrillary tangles (fig 2), particularly in the deep cortical layers. A slightly higher density of neurofibrillary tangles was seen at this site in patient III.4. Immunohistochemistry with an $\mathrm{A} \beta$ protein antibody showed many senile plaques (fig 3), across the temporal cortex in patient III.3; senile plaques were less numerous in patient III.4 and more prevalent in the superficial cortical layers (fig 4). The occipital lobes of both cases contained only a few neurofibrillary tangles and moderate numbers of senile plaques. Notably, diffuse plaques in the cerebellum were striking features of both cases (fig 5). Senile plaques are occasionally seen in the cerebellum in sporadic Alzheimer's disease, but the density seen in these two patients is unusual. Large numbers of cerebellar senile plaques have also been reported in a kindred with an E280A substitution in the PS1 gene. ${ }^{24}$

The density of neurofibrillary tangles was particularly high in the amygdalae and hippocampi, and a moderate number of neurofibrillary tangles were found in the nucleus basalis of Meynert. However, neurofibrillary tangles in 


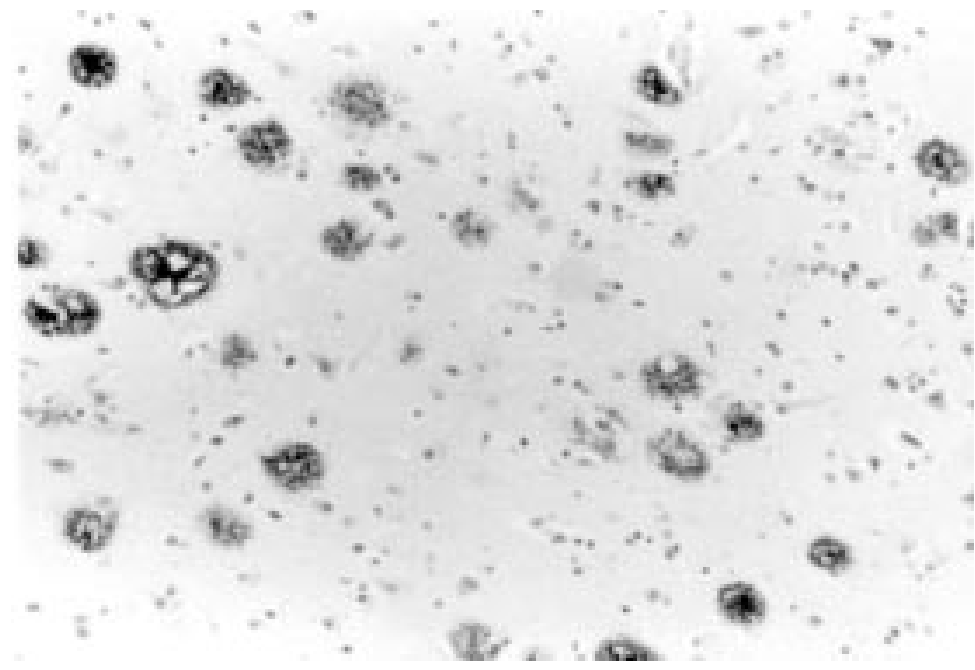

Figure 4 Patient III.4. Abundant classic senile plaques were seen in many cortical areas; this is the superior temporal gyrus ( $A \beta$ protein antibody).

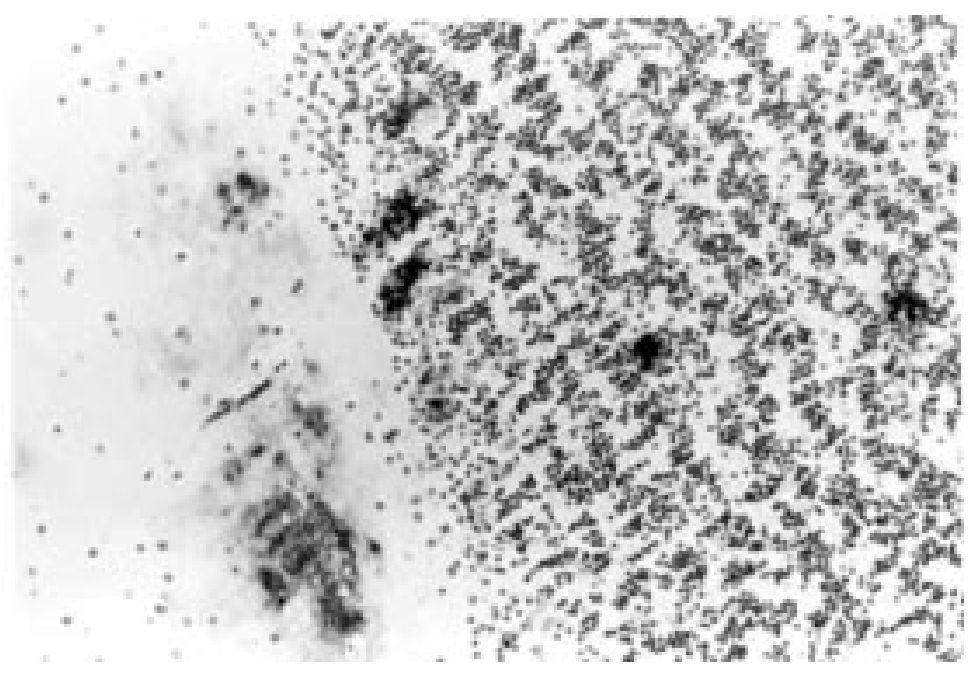

Figure 5 Patient III.3. Diffuse senile plaques in the molecular layer and circumscribed accumulations of $A \beta$ protein in the internal granular layer of the cerebellum $(A \beta$ protein antibody).

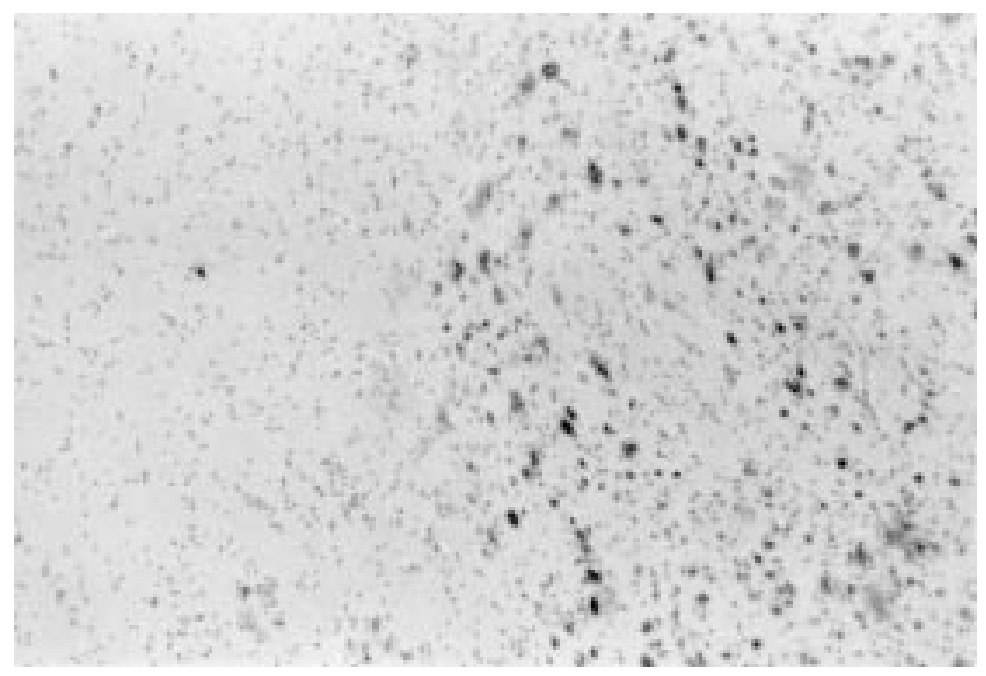

Figure 6 Patient III.4. The presence of abundant senile plaques in the putamen contrasts with the paucity of senile plaques in the adjacent globus pallidus. The same phenomenon was also noted in patient III.3 ( $A \beta$ protein antibody). the pre- $\alpha$ areas of the subiculum were very sparse, which would be an unusual appearance for sporadic Alzheimer's disease; moreover, these are areas often considered to be always involved early in Alzheimer's disease. ${ }^{25}$

Large numbers of small diffuse "cloud-like" plaques were seen in the region of the nucleus basalis of Meynert in both patients, another unusual finding in sporadic Alzheimer's disease. Both patients showed a selective distribution of senile plaques and neurofibrillary tangles in the deep grey nuclei. The putamen contained many senile plaques which contrasted with a paucity of senile plaques in the globus pallidus (fig 6). In both patients neurofibrillary tangles were plentiful in the midline nuclei of the thalamus, but were scarce in the dorsomedial nucleus.

The cerebellar cortex contained scattered foci of diffuse plaques and Bergmann gliosis. A few neurofibrillary tangles were seen in the locus coeruleus and nucleus centralis superior. Patient III.4 showed more neurofibrillary tangles than patient III. 3 in the dorsal raphe.

\section{Discussion}

Before the cloning of the PS1 gene it was generally considered that most families with chromosome 14 familial Alzheimer's disease had an age at onset in the 30s and 40s; however, the pedigree reported here has a median age at onset of 51 (range 49 to 56) years. Reviewing 38 published pedigrees with 22 PS 1 mutations; seven pedigrees had a mean age at onset in the 30s; 21 in the 40s; and for 10 families, in the $50 \mathrm{~s}$. In general the age of onset is determined by both the site and nature of the mutation, the few families with the same mutation having very similar ages of onset. ${ }^{26}$

Of the patients described here, clinical information available suggested features broadly typical of Alzheimer's disease. However, comparing more subtle features of their presentations suggests a particular phenotype for this mutation.

Myoclonus was a particularly pronounced feature in the three members on whom we have detailed medical information. In one member the involuntary movements were of such intensity that a clinical diagnosis of Huntington's disease was briefly considered. None of the members experienced seizures, which have been a prominent feature of other chromosome 14 familial Alzheimer's disease pedigrees, ${ }^{18} 2728$ and have been noted to develop in parallel with the myoclonus. ${ }^{17}$ In two families with PS1 M139V mutations, myoclonus and seizures were a feature common to all affected members, with the myoclonus starting, on average, three years before the seizures. ${ }^{29}$ The reduced incidence of seizures may simply reflect the older age at onset in this family compared with other PS1 families that have been described. Mayeux et $a l^{30}$ noted that patients with myoclonus were of younger onset.

Neuropathological findings in the two affected members were similar to other cases of familial and sporadic Alzheimer's disease. This is consistent with previous studies comparing familial Alzheimer's disease and the sporadic 


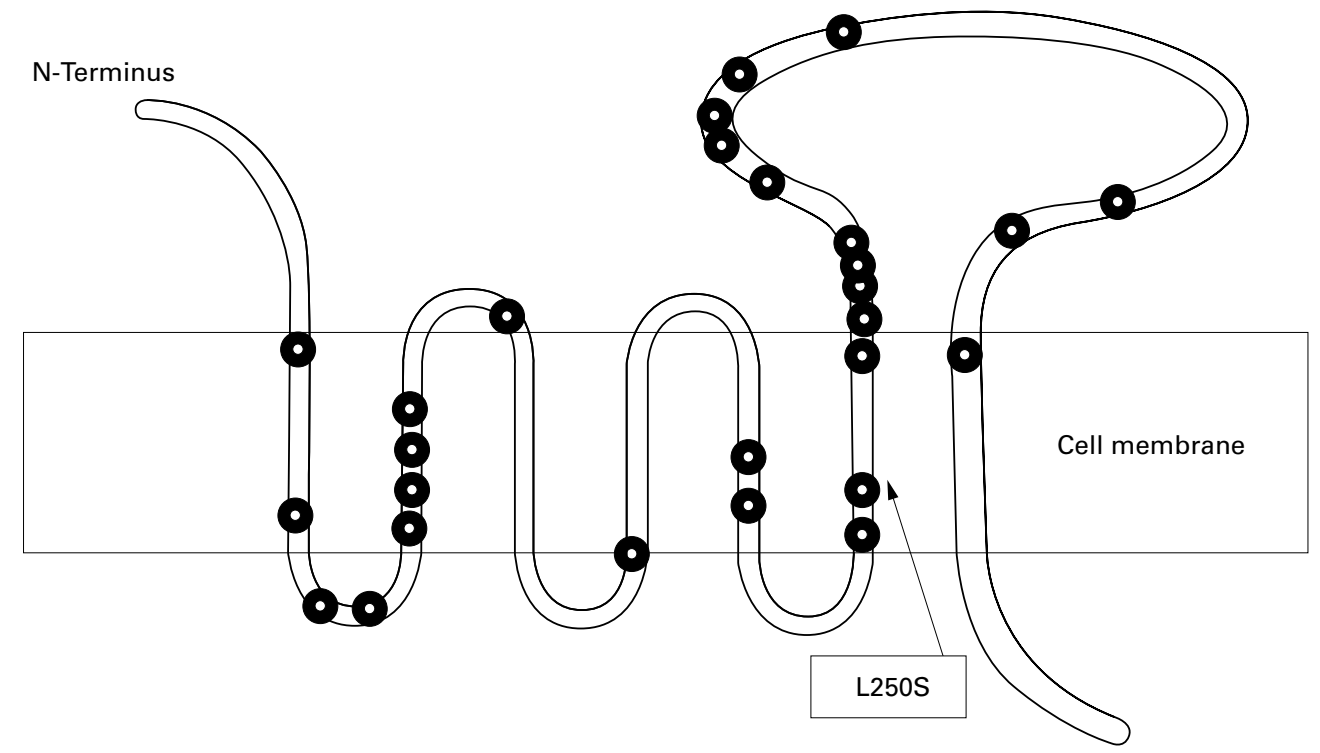

Figure 7 Putative structure of the PS1 gene showing the site of the known mutations, with estimated site of the L250S mutation indicated.

form which have not disclosed any significant differences in $\mathrm{A} \beta$ protein deposition using quantitative analysis, ${ }^{31}$ and with immunohistochemical studies that have shown familial Alzheimer's disease and sporadic Alzheimer's disease to have the same cytoskeletal pathology. $^{32}$

More than $50 \%$ of early onset familial Alzheimer's disease is likely to be associated with mutations in the PS1 gene. After the initial cloning of the gene, ${ }^{8}$ at least 31 PS1 mutations have now been identified. ${ }^{5-11} 15162633$ The structure of the PS1 gene product has been predicted to be a 467 amino acid length integral membrane protein with between six and nine transmembrane domains. Figure 7 illustrates a hypothetical model of the protein with seven transmembrane domains. ${ }^{26}$ The sites of known mutations, including L250S, are indicated, and it is notable that most of these are in close proximity to the transmembrane domains.

Further descriptions of PS1 mutation pedigrees will allow us to build up a picture of the function of the gene as related to its structure. A homologous gene has recently been located on chromosome 1 (PS2) $)^{14}$ and is associated with the Volga German familial Alzheimer's disease pedigrees. Both PS1 and PS2 have been predicted to have similar gene products and it is likely that the mutations identified are interfering to a variable extent with the biological function of these proteins; however, the normal function of the presenilin proteins and their interactions with amyloid precursor protein are yet to be understood. Recent reports have begun to examine $A \beta$ protein production in primary fibroblasts from families with chromosome 14 linked familial Alzheimer's disease; these have shown that PS1 mutations can cause alterations of $B$ amyloid precursor protein processing, resulting in the increased production of the longer form of $A \beta_{1-42}$ (42 rather than 40 amino acids in length) that is associated with Alzheimer's disease. ${ }^{34}{ }^{35}$ These findings have also been confirmed in plasma samples from some of these patients. A recent finding of a single base pair intronic polymorphism of the PS1 gene in late onset sporadic Alzheimer's disease cases of United Kingdom origin ${ }^{36}$ suggests that the presenilin genes may have a wider role in the many sporadic cases of Alzheimer's disease.

We have described the clinical features of a family with a novel PS1 L250S mutation. There are currently few published clinical descriptions of families affected by PS1 familial Alzheimer's disease and in view of the wide range of mutations in this gene it is unlikely that there will be many affected persons with any one mutation. However, it is hoped that the comparison of the clinical features of the various mutations may begin to provide insights into the function of the presenilin proteins.

The clinical implication from this report is that patients with dementia presenting with a strong family history of Alzheimer's disease, even in the absence of a large pedigree, in whom the disease starts between the ages of 30 and 60 years should be considered for genetic counselling and screening for PS1 mutations. The current recommendations of the United Kingdom Alzheimer's disease Genetics Consortium are that genetic testing for Alzheimer mutations should follow the protocol established for Huntington's disease.

1 Rossor MN. Molecular pathology of Alzheimer's disease. $\mathcal{F}$ Neurol Neurosurg Psychiatry 1993;56:583-6.

2 Goate A, Chartier Harlin M, Mullan M, et al. Segregation of a missense mutation in the amyloid precursor protein gene
with familial Alzheimer's disease. Nature 1991;349:704-6.

3 Schellenberg GD, Bird TD, Wijsman EM, et al. Genetic linkage evidence for a familial Alzheimer's disease locus on chromosome 14. Science 1992;258:668-71.

4 Mullan $\mathrm{M}$, Houlden $\mathrm{H}$, Windelspecht $\mathrm{M}$, et al. A locus for familial early-onset Alzheimer's disease on the long arm of chromosome 14, proximal to the $\alpha 1$-antichymotrypsin gene. Nat Genet 1992;2:340-2.

5 Alzheimer's Disease Collaborative Group. The structure of the presenilin I (S182) gene and identification of 6 novel mutations in early onset AD families. Nat Genet 1995;11: mutations 
6 Tanahashi H, Mitsunaga y, Takahashi K, Tasaki H, Watanabe S, Tabira T. Missense mutation of S182 gene in
Japanese familial Alzheimer's disease. Lancet 1995;346: Japan.

7 Sorbi S, Nacmias B, Forleo P, et al. Missense mutation of S182 gene in Italian families with early onset Alzheimer's disease. Lancet 1995;346:439-40.

8 Sherrington R, Rogaev EI, Liang Y, et al. Cloning of a gene bearing mis-sense mutations in early-onset familial Alzheimer's disease. Nature 1995;375:754-60.

9 Cruts M, Backhovens H, Wang SY, et al. Molecular-genetic analysis of familial early-onset alzheimers-disease linked to chromosome 14q24.3. Hum Mol Genet 1995;4:2363-71.

10 Wasco W, Pettingell WP, Jondro PD, et al. Familial Alzheim-
er's chromosome 14 mutations. Nature Medicine 1995;1: 848 .

11 Campion D, Flaman JM, Brice A, et al. Mutations of the presenilin I gene in families with early-onset Alzheimer's presenilin I gene in families with early-

12 Perez-Tur J, Froelich S, Prihar G, et al. A mutation in Alzheimer's disease destroying a splice acceptor site in the imer's disease destroying a splice acceptor

13 Hutton M, Busfield F, Clark RF, et al. Complete analysis of the presenilin 1 gene in families with early onset Alzheimer's disease. Neuroreport 1996;7:801-5.

14 Levy-Lahad E, Wasco W, Poorkaj P, et al. Candidate gene for the chromosome 1 familial Alzheimer's disease locus Science 1995;269:973-7.

15 Rogaev EI, Sherrington R, Rogaeva EA, et al. Familia Alzheimer's disease in kindreds with missense mutations in a gene on chromosome 1 related to the Alzheimer's disease type 3 gene. Nature 1995;376:775-8.

16 Boteva K, Vitek M, Mitsuda H, et al. Mutation analysis of presenilin

17 Lampe TH, Bird TD, Nochlin D, et al. Phenotype of chromosome 14-linked familial Alzheimer's disease in a large kindred. Ann Neurol 1994;36:368-78.

18 Kennedy AM, Newman SK, Frackowiak RSJ, et al. Chromosome 14 linked familial Alzheimer's disease: a
clinico-pathological study of a single pedigree. Brain 1995; 118:185-205.

19 Farrer LA, Myers RH, Cupples LA, et al. Transmission and age-at-onset patterns in familial Alzheimer's disease: evidence for heterogeneity. Neurol 1990;40:395-403.

20 Folstein M, Folstein S, McHughs P. The mini mental state: a practical method for grading the cognitive state of patients for the clinician. I Psychiatr Res 1975;12:189-98.

21 Hughes CP, Berg L, Danziger WL, et al. A new clinical scale for the staging of dementia. Br F Psychiatry 1982;140:56672 .

22 Medical Research Council. Report from the MRC Alzheimer's disease workshop. London: HMSO, 1986.
23 Clark RF, Cruts M, Korenblat KM, et al. A yeast artificial chromosome contig from human chromosome 14q24 spanning the Alzheimer's disease locus AD3. Hum Mol Genet 1995;4:1347-54.

24 Lamere CA, Lopera F, Kosik KS, et al. The E280A presenilin 1 Alzheimer mutation produces increased Ab42 deposition and severe cellular pathology. Nature Medicine 1996;2: 1146-50.

25 Braak H, Braak E. Diagnosis of Alzheimers-disease - development of cytoskeletal changes and staging of Alzheimer related intraneuronal pathology. Neurobiol Aging 1994;15: S141

26 Cruts M, Hendriks L, Van Broeckhoven C. The presenilin genes: a new gene family involved in Alzheimer disease pathology. Hum Mol Genet 1996;5:1449-55.

27 Frommelt P, Schnabel R, Kuhne w, Nee LE, Polinsky RJ. Familial Alzheimer disease: a large, multigeneration German kindred. Alzheimer Dis Assoc Disord 1991;5:36-43.

28 Haltia M, Viitanen M, Sulkava R, et al. Chromosome 14-encoded Alzheimer's disease: genetic and clinicopathological description. Ann Neurol 1994;36:362-7.

29 Fox NC, Kennedy AM, Harvey RJ, et al. Clinicopathological features of early onset familial Alzheimer's disease associated with the M139V mutation in the presenilin 1 gene. Brain 1997;120:491-501.

30 Mayeux R, Stern Y, Spanton S. Heterogeneity in dementia of the Alzheimer type. Evidence of subgroups. Neurol 1985;35:453-60.

31 Cairns NJ, Chadwick A, Lantos PL, Levy R, Rossor MN. Beta A4 protein deposition in familial Alzheimer's disease with the mutation in codon 717 of the beta A4 amyloid precursor protein gene and sporadic Alzheimer's disease. Neurosci Lett 1993;149:137-40.

32 Lantos PL, Luthert PJ, Hanger D, Anderton $\mathrm{BH}$, Mullan $M$, Rossor M. Familial Alzheimer's disease with the amyloid precursor protein position 717 mutation and sporadic Alzheimer's disease have the same cytoskeletal pathology. Neurosci Lett 1992;137:221-4.

33 Van Broeckhoven C. Presenilins and Alzheimer's disease. Nat Genet 1995;11:230-2.

34 Scheuner D, Song X, Suzuki N, et al. Fibroblasts from carriers of familial $\mathrm{AD}$ linked to chromosome 14 show increased AB production. Soc Neurosci 1995;21:1500.

35 Querfurth HW, Wijsman EM, St George Hyslop PH, Selkoe DJ. Beta APP mRNA transcription is increased in cultured fibroblasts from the familial Alzheimer's disease-1 family. Brain Res Mol Brain Res 1995;28:319-37.

36 Wragg $M$, Hutton $M$, Talbot $\mathrm{C}$, et al. Genetic association between intronic polymorphism in presenilin-1 gene and late-onset Alzheimer's disease. Lancet 1996;347:509-12. 